\title{
New Dimension of Tourism in the Era of New Media in Oman: A Case Study based on Salalah
}

\author{
By Dr. Sangeeta Tripathi \& Ms. Muna Al Shahri \\ College of Applied Sciences
}

Abstract- In the era of new media, people and societies across the globe are interconnected and extending the new framework to business, trade, and tourism. Different websites and social media are facilitating a plethora of content and information through photos, videos, 3D visualization to satisfy people's queries, to promote and brand nations. Due to this, tourism is also witnessing a big change. Oman is not far away from this reality. This study aims to gauge into the present tourism status of Oman and its prospects. It will examine the pervasiveness of new media and its increasing significance in holding the desired position in the world-class tourism. Observation and survey methods are applied to reach out the result. Total 125 samples have been collected through an online created link from Salalah to understand the mass thinking about new media and its changing role in the tourism sector. The findings provide insight understanding about the current situation of tourism; despite all efforts of Tourism Ministry and increasing penetration of new media, more efforts and awareness are required in terms of the involvement of locals to make Oman international tourism destination.

Keywords: marketing tool, new media, online marketing, tourism, visual effect etc.

GJHSS-A Classification: FOR Code: 200206

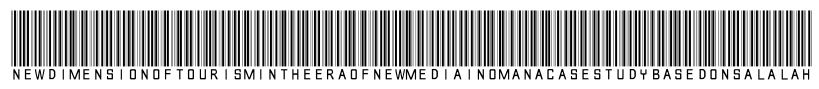

Strictly as per the compliance and regulations of:

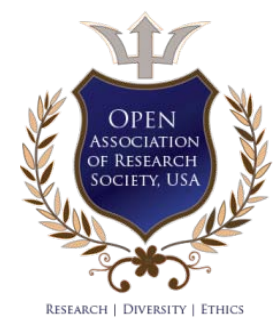

(C) 2019. Dr. Sangeeta Tripathi \& Ms. Muna Al Shahri. This is a research/review paper, distributed under the terms of the Creative Commons Attribution-Noncommercial 3.0 Unported License http://creativecommons.org/licenses/by-nc/3.0/), permitting all noncommercial use, distribution, and reproduction in any medium, provided the original work is properly cited. 


\title{
New Dimension of Tourism in the Era of New Media in Oman: A Case Study based on Salalah
}

\author{
Dr. Sangeeta Tripathi $\alpha$ \& Ms. Muna Al Shahri $\sigma$
}

\begin{abstract}
In the era of new media, people and societies across the globe are interconnected and extending the new framework to business, trade, and tourism. Different websites and social media are facilitating a plethora of content and information through photos, videos, 3D visualization to satisfy people's queries, to promote and brand nations. Due to this, tourism is also witnessing a big change. Oman is not far away from this reality. This study aims to gauge into the present tourism status of Oman and its prospects. It will examine the pervasiveness of new media and its increasing significance in holding the desired position in the world-class tourism. Observation and survey methods are applied to reach out the result. Total 125 samples have been collected through an online created link from Salalah to understand the mass thinking about new media and its changing role in the tourism sector. The findings provide insight understanding about the current situation of tourism; despite all efforts of Tourism Ministry and increasing penetration of new media, more efforts and awareness are required in terms of the involvement of locals to make Oman international tourism destination.
\end{abstract}

Keywords: marketing tool, new media, online marketing, tourism, visual effect etc.

\section{InTRODUCTION}

I $\mathrm{n}$ the era of new media, business and tourism have totally migrated from traditional analog to the world of technology. Globalization process has extended marketplace from one country to the whole world. Plenty varieties of branded products are available which is actually intensifying competitiveness and raise many challenges to different industries of one country. The Internet has connected heterogeneous societies across the world and extending the new framework to trade and tourism

Oman is not untouched with global changing reality. To cantering with the modern development process, Oman has also adopted the online system. After 25th May 2009 onwards, government offices, ports, aviation, telecom services, other private companies, and bank institutions have started emphasizing on the main gateway to electronic postal service. With the advent of smartphones, the use of social media has increased rapidly by $85.9 \%$. WhatsApp is the most popular application with 87.9\%; Facebook holds second positions with $79.1 \%$ and You Tube with $65.4 \%$. On the

Author a $\sigma$ : College of Applied Sciences, Salalah. e-mails: sangeeta.sal@cas.edu.om,muna-alshahri.sal@cas.edu.om other hand, due to economic reform, the government pushed tourism as an industry by investing the huge amount of their revenue. The tourism sector is encouraging as it has shared $2.8 \%$ of GDP in 2015 (COMCEC, 2015). It has produced 44,000 direct jobs in 2014 and it is a forecast estimated that it will reach 72,000 by 2025 (Muscat Daily, 2015). These two points have dragged our prime attention for further study.

\section{il. Objectives of the Study}

Major objectives of the paper are:

a) To gauge into the present tourism status and its prospects.

b) To understand the pervasiveness of new media and its significance in holding the desired position in the world-class tourism.

\section{ili. Literature Review}

Some research studies show how media and tourism work together hand in glove and plethora available online information, pictures, videos and 3D visual impact far away latent tourist in suggesting destinations and facilitating other services by reducing risk. According to a survey in 2013 for the significance of social media marketing in tourism, $40 \%$ people surf the net to select their destination while $87 \%$ surf for hotel and accommodation. Furthermore, 84\% try net for getting information for travel methods. The 78\% people use the net to know about food and beverage while $84 \%$ people surf the net for selecting interesting spots to be covered during their visit. The 50\% and 57\% people use the net for reading blogs to know about the place and see travel related website to read reviews. It helps in branding a nation and place opinion about a destination (Jarshi, 2013).

\section{a) Brand Oman as a Tourist Destination}

Oman as a beautiful nation owns all necessary requirements which are required for branding a nation as a tourist destination. The advertising, publicity, promotion and different marketing communication strategies help to improve the positive image. To promote brand Oman, a management unit had been launched in 2009 by Public Authority for Investment Promotion and Export Development. It is Called Brand Oman Management Unit (BOMU) (Hafiz Abad Institute of Business Administration, 2016). Its sole aim is to 
brand Oman as a tourist destination. It provides cogent strategic communication for media relation and marketing to the Tourism Ministry. It does not involve in straightforward advertising for the country plans (MacDonald, 2014).

To give force to tourism initiative, the Oman government has worked on tourists' facilitates establishments and developed Salalah in late 2000, as major tourists destination (CME, 2010). Major tourism projects are taking place such as Muscat and Salalah Airport, Jebel Sifah Complex, Al Sodah Island, Salalah, Salam Yiti Resort, City Hotel, Duqm Hotel Project, Fort Hotel, Oman Convention and Exhibition Centre, Saraya Bander Jissah Project, Mall of Oman, Duqm Fisheries Industrial Zone, Kempinski Wave Hotel, Muscat Palm Mall and JW Mariott Hotel Projects etc. In 2015, it was 1570. The 92 licenses for travel agencies and 8 licenses for outdoor activities (such as sea sports centers and diving clubs, rental boats and water bikes) were issued in the same year (Food and Hospitality Oman, 2016).

b) Significance of PR and Advertising in Business and Tourism in Oman

Due to global changing communication demand, prudent industrialists and tourism professional consider PR and advertising services compulsory. It shows their curiousness towards perceiving the value of products and services. This leads professionals to seek solutions in the field of web advertising, graphic designing, and event management. This can be counted as a reason for increasing number of $\mathrm{Ad}$ and $\mathrm{PR}$ agencies in the Sultanate.

Table 1: Increasing registration of Ad and PR Agencies

\begin{tabular}{|c|c|}
\hline Year & Registered Ad and PR Agencies \\
\hline $2010-2011$ & 64Ad \& PR agencies were registered \\
\hline 2013 & 19 more ad Agencies Got registered \\
\hline 2014 & 16 more ad Agencies Got registered \\
\hline 2015 & 19 more ad Agencies Got registered \\
\hline
\end{tabular}

(Source: Ministry of Information, 2015 as cited in Tripathi, 2016)

Tripathi (2016) illustrates that the significance) PR and Advertising agencies in a new framework of business and tourism is increasing but they are not playing an active role in the tourism sector to push as it is required. These ad agencies are more into the business of gift and publication rather than directly working for tourism.

\section{Use of New Media in Oman Tourism TO Aspire, TOURists}

Tourism Ministry is working hard in promoting distinct attractive features of the Omani culture and heritage with beautiful marvelous sight scenes to make tourists experience great and aspire to visit Oman again for different reasons. In view of techno-savvy latent virtual tourists, the ministry has a comprehensive communication strategy plan that's why they have hugely included new media in its official communication plan. With a comprehensive assessment, the Tourism Ministry aims to have 12 million visitors by 2020. They keep informing about activities through their official website and Facebook link for the virtual tourists. The ministry is promoting Oman under the tagline- "Beauty has an address- Oman". The Ministry website display visual content, animations and virtual tour to mesmerize far away web visitors. It provides information related to different locations such as Al Kasfah, Bandar Khayran, Jabal Shams, Jabal Al Akhtar, Mutrah Corniche, Sand landscape, coral reef, mountain, wadis, clean beaches, agricultural village, turtle reserve etc. (MOT, 2016). Brand Oman Management Unit is also playing a prominent role, as it has a brand center- an online system. It ensures the uniformity in implementing the several applications of the brand. The website has a link for quick reference, relates Oman government authorities, hospitality, other services and media of the country. It helps not only locals but international partners and tourist to explore knowledge and information about Oman.

Tourism Ministry is also focusing on south vibrant city Salalah as it has a unique kind of monsoon (Campaign Middle East, 2010). From June to August, continue drizzling turns Salalah Mountains and landscapes into verdure. Temperature also dips down 20-25 degree Celsius. Salalah has new well equipped modern International Airport to attract more national and international tourists. Dhofar governorate celebrates very year "Khareef Festival" and promotes it through different print, electronic and new media channels. Many social, cultural, sports, entertainment events, handcraft, art, game, traditional village, meal and other activities are being organized. Our area of research is also related to Salalah Khareef tourism as we have noticed that every year large numbers of tourists visit Salalah during Khareef which includes a large number of Omanis residents from different cities rather than International tourists.

\section{Oman Tourist Data at a Glance}

If we look into to chronicle data released from the National Centre for Statistics and Information (NCSI), it will be clearer. 
Table 2: Year-wise tourist data including Omani visitors to Dhofar

\begin{tabular}{|c|c|c|c|}
\hline Year & Total Number of Visitors & The share of Omanis' Visitors & $\begin{array}{c}\text { Percentage of Total } \\
\text { Visitors }\end{array}$ \\
\hline 2012 & 351,195 & 211,042 & $60.1 \%$ \\
\hline 2013 & 433,639 & 298,749 & $68.9 \%$ \\
\hline 2014 & 431,105 & 327,000 & $75.8 \%$ \\
\hline 2015 & 462,424 & 342,579 & $74 \%$ \\
\hline 2016 & 652,986 & 447,713 & $70.5 \%$ \\
\hline
\end{tabular}

(Source: National Centre for Statistics and Information, 2016, as cited in Oman Turbine, 2016)

Table No.2 shows pretty good improvement in the total number of tourists each year after 2012. According to NCSI data, the highest ever figure of tourists before 2015 were recorded in 2008. It was 450,511 . Afterward, a declined was noticed due to H1N1 influenza, economic recession, and Ramadan coinciding with Khareef season. That's why, visitors numbers were registered 293,043 in 2009, 262,203 in 2010, and 339,500 in 2011. The Tourism Ministry efforts are well rewarded after 2013 as travel and tourism industry has generated 44,500 jobs during 2014 in the field of hotel, hospitality, travel agents, airlines, local commuter services, leisure, and other entertainment activities to the tourists. Most of Muscat and Salalah based private hospitality ventures are hugely connected with virtual customers through websites and other social applications. Several international hotel booking sites like India based MakeMyTrip.com, Germany basedtrivago.com, Amsterdam, Netherland based booking.com and Massachusetts, US-based tripadvisor.com are also facilitating different types of accommodation needs to national and International tourists. This impact can be seen on the visitors' number.

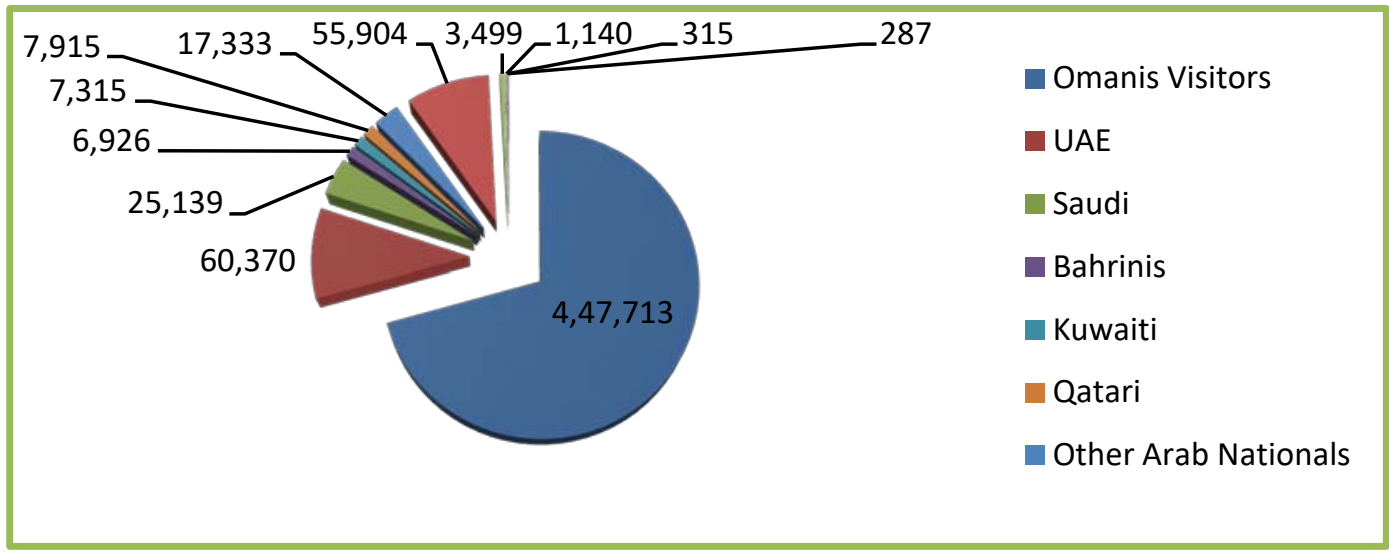

(Source: ONA and NSCI, 2016)

Fig. 1: Tourists share of 2016 Khareef according to their nationalities

Table 3: Tourists share table data of 2016 Khareef according to their nationalities

\begin{tabular}{|c|c|c|c|c|c|}
\hline Omanis Visitors & UAE & Saudi & Bahrainis & Kuwaiti & Qatari \\
\hline 447,713 & 60,370 & 25,139 & 6,926 & 7,315 & 7,915 \\
\hline Other Arab Nationals & Asian Visitors & Europe & Americans & Africans & Oceania \\
\hline 17,333 & 55,904 & 3,499 & 1,140 & 315 & 287 \\
\hline
\end{tabular}

(Source: national newspaper, ONA and NSCI, 2016)

Fig.1. and Table.3 show a big number of Omanis tourists who share a big chunk of total tourists. By the above data and description, it becomes clear that the number of tourists is increasing steadily but international tourist's ratio is lower than Omani tourists. During a discussion with locals, we found that summer temperature becomes 50c or more in Muscat, Nizwa,
Ibri, Sur and Sharkiyah while Salalah and its mountains become 20 to 30 degree Celsius cooler. Sight scenes and lush Green Mountain lure them to come here to spend their holidays. First few weeks, the flux of the tourists is not more. Actually, national visitors wait for their Facebook and other social application groups to be updated with photos and videos of the place by their 
friends, relatives and known. After receiving input, they flock to visit Dhofar Khareef. It can be counted as a reason to shoot up a native visitor's ratio in Khareef.

\section{Tourism EfForts and Approach}

Now the question is -what more efforts can be done in the area of boosting up international tourism in the Sultanate. But before discussing this question, it becomes significant to understand the types of approaches towards tourism. There are two types of approach- Higher End Tourism and Mass Tourism. Higher end tourism appeals to sophisticated intellectual class travelers who seek for discerning beauty of nature. It is expensive while Mass tourism always refers to a large influx of tourists. It is the cheapest way to have a package deal for holidays (Zlatareva, 2015). For example- Dubai Tourism Statistics shows that Dubai is the 4th most visited city in the world. After London, Paris, and Bangkok, tourists want to go to Dubai.

Table 4: Year-wise an Estimate number of Tourists in Dubai

\begin{tabular}{|l|c|c|c|c|}
\hline Year 2011 & Year 2012 & Year2013 & Year2014 & Year2015 \\
\hline 9.3 Million & 10 Million & 11 Million & 13.2Million & 14.3Million \\
\hline
\end{tabular}

(Source: go-gulf.ae data, 2015)

Table No.4 shows that Dubai tourism has attracted mass tourists in passing years. As the mass marketing approach, Dubai has recreated tourists spots with different events, services, food, beverage, cultural programmes, craftsmanship, travel trade, travel guide, transportation, electronic markets, and conferences. They have developed adventure along with their landscape. Tourists visit for sighting scenes, entertainment and business purposes

Oman is still following higher-end tourism rather than a mass-market approach. The best months are to visit Oman start from November to March. But this visit is limited to capital city Muscat and north part of Oman as its weather is suitable for the tourists. Mutrrah Croniche, Qantab and Qurum Beach, Turtle and Dolphin land, Sultan Qaboos Grand Mosque, Muscat Opera house, traditional gold, and silver souk, fully blooming public garden with a different variety of flowers lure tourist to stay there more while Salalah has an opposite time to visit from June mid to August last. If travel agents connect Salalah tourism with Muscat, they include Al Baleed Archaeological Park, and places like Samhram, and Muqusail from Salalah which can be covered in one day visit which is sufficient to display Salalah beauty (Wippel, 2015). Dhofar has vast potential to be explored as it has a unique combination of natural treasuremountain, clean beaches, coconut tree, banana gardens, beautiful monsoon, seasonal waterfalls, wadis (canals and channels), and deserts. But it is all charm and beauty entices tourists in a specific time. This huge potential of Dhofar tourism can be utilized not only in specific season but the whole of the year if Salalah's different tourist spots are recreated with adventures, different events, services, food, beverage, cultural programmes, craftsmanship, travel trade, travel guide, and transportation. Salalah is only the place in GCC, where the weather is fine for all most 9 months. Maximum temperature goes up to 35c. This is another big reason to promote Dhofar tourism. During the winter season, different types of birds migrate from western countries to Salalah. For bird watchers, birds' centuries can be developed along with wildlife attraction. Rub Al Khali- empty quarters can be promoted on a vast level as it is suitable for camping overnight, stargazing, and dun bashing adventure. There are very minimal numbers of local travel agents who use to arrange a few activities but these activities are drops in the ocean as they are not known to the latent tourists.

Along with Dhofar weather, its biggest treasure is its well-curved mountains and their helicoids ways, where mountain bicycle route can be developed to encourage bicycle sports. Mountaineering, training for walking on the rope can be other adventurous events for the tourists. Locals can be made aware and trained to promote these activities. In lack of such awareness, locals may astonish and this may be a reason to bother and discourage tourists. If these efforts are done on the floor and connect with a different website and social sites, it will help to inform the world abut unexplored potential of Dhofar. Muscat-based travel agent needs to give equal attention while preparing a tour package to different countries' tourists. Along with this, Dhofar locals should also come forward with such agencies to make available an enjoyable tourism experience to call International tourists again and again.

\section{Vil. The Scope of New Media as Marketing TOOL in TOURISM AND ITS IMPACT ON MASS THINKING}

New Business module is transitioned from a top-down messaging model to networked world as different advanced communication channels have started connecting heterogeneous societies across the globe. It has offered immense scope for online marketing communication (MEDIATE report, 2016). Tourism and hospitality industry is targeting technosavvy real and virtual public across the world. New 
customers want to know all types of information beforehand such as destination and hotel information, service providers' commitments towards services, customers reviews, a method of travel, interesting spots to be covered during a visit, local transportation, and tourism and guiding supports services beforehand. To fulfil these requirements, a cogent communication strategy needs to be created and through different social media platform, meaningful content and information can be uploaded. It includes traveler blogs, websites, photo and video sharing site, podcast, webcast channels and different social networking sites such as Facebook, Twitter, and Instagram. Social sites navigate visitors with right travel information, personalized with direct interest message according to their demand.

Social Media advertising and marking approach is a cost-effective way for any industry as they can set their objectives, display their mission and vision for maximum transparency and arrange feedback for the betterment of their services. This kind of transparency is liked by new era customer, that's why such sites achieve higher credibility from the target public. This trust becomes more power packed as new media big brands are getting advertised on print and electronic media on the national and International level. This encourages tourists to book their wide range of services and products through the most trusted and transparent websites such as Trip Advisor, Trivago.com, Booking.com, MakeMyTrip.com, and Thomascook.com etc. Facebook and other social sites are utilized to promote these websites. It encourages travelers to plan their holidays by sitting in comfort without any worry. According to a deal between service providers and website management, customers are also getting very good packages, incentives, and add-on services at the same paid price. Now, these websites are providing good cancellation schemes also which gives a sense of security in terms of money to the target public. America like the developed country has also launched their website thebrandUSA.com and discoverAmerica.com in 2012 to promote their country tourism. Due to this marketing strategy, USA has supported 50,000 increments in US jobs per year (Brand USA, 2016).

Table 5: Population of Oman and Internet use year by year

\begin{tabular}{|c|c|c|c|c|}
\hline Year & Oman Total Population & Internet Users & Non Internet Users & Penetration (\% of Population) \\
\hline 2011 & $3,210,003$ & $1,540,801$ & $1,669,202$ & $48 \%$ \\
\hline 2012 & $3,545,192$ & $2,127,115$ & $1,418,077$ & $60 \%$ \\
\hline 2013 & $3,906,912$ & $2,596,143$ & $1,310,769$ & $66.5 \%$ \\
\hline 2014 & $4,236,057$ & $2,974,559$ & $1,261,498$ & $70.2 \%$ \\
\hline 2015 & $4,490,541$ & $3,181,228$ & $1,309,313$ & $70.8 \%$ \\
\hline 2016 & $4,654,471$ & $3,310,260$ & $1,344,211$ & $71.1 \%$ \\
\hline
\end{tabular}

(Source: Internet live State)

Table No. 5 shows that internet use in Oman is increasing year by year and touched $71.1 \%$ in July 1 st, 2016 (Internet Live Stats, 2017). It displays a great potential to connect online mass marketing tourism. This can be utilized as an opportunity and can be connected with tourism and its sub-sections such as transportation accommodation, tourism support, guiding services, recreated attraction, events, and adventure together to help in generating the target employment on the local and national level by 2025. It helps in generating support for other business like the sale of traditional items, craft and entices women visitors to purchase different fancy accessories. Sponsorship and adverting in different countries media and events also help to maximize the mass marketing approach.

\section{Vili. Methodology}

The study is based on survey and observation methods. The random sampling technique is applied to collect data from Salalah. The questionnaire consists of total ten close-ended questions which aim to provide relevant information about the expanding use of new media, its changing role, mass thinking about tourism and its obstacles. The questionnaire has been prepared in Arabic and English languages to facilitate understanding regarding different tourism terms. The questionnaire has been circulated among 200 people through an online created link and we could receive 125 responses. The response targets between two age groups- below 30 and above 31, new media users. The data are analyzed by using the descriptive method in a percentage of frequency for the responses. News and other online portals have been chosen for our study under observation method. Total ten videos have been reviewed. The criteria of selection for the videos areseeing Oman through the world's eyes and participation of locals in promoting Oman tourism. 


\section{iX. Data Analysis and Discussion}

Each question is carrying one research variable such as- age, expanding the use of social media, its changing role, mass thinking about tourism, its obstacles, and awareness of tourism benefits. The 125 responses are analyzed by using the descriptive method in a percentage of frequency for the responses.

The majority of the respondents below 30 age $(83.47 \%)$ say that they use social media. They believe that new media has all potential to be utilized as a marketing tool; while above 31 age group (16.53\%) respondents are in between to some extent and no.

In answer to a question of considering new media as a tool to promote national and international tourism in the country, $86.78 \%$ respondents say that new media has emerged as a new platform where we can connect with the world online through photos, videos, and other content. This gives an idea about the places, people and their cultural heritage. But $8.26 \%$ respondents believe that along with the photo, videos, and content, podcasting webcasting can also be very helpful in promoting tourism of the country, while $4.9 \%$ respondents say that online interaction will be more forceful for this sector.

The majority of respondents (51.30\%) say that Social media content and picture motivate them to plan their holidays. They say that during Khareef, many photos and visuals of different places like Darbat, Hamran, Mughsail, and other unrevealed captivating landscapes from Salalah have been shared through Facebook, Instagram, and WhatsApp by one to another and encourage them to visit that destination. That's why a big jump in visitors' number has been noticed after the third week of Khareef. The $22.61 \%$ respondents indicate that sometimes it depends on the visuals, while $26.9 \%$ say that they never go for this.

In answer to a question about why social media force them to travel more, $47.32 \%$ respondents say that they want to be active on social media to show their cool lifestyle and also to explore the nature. It improves their social status among their groups and community. The $37.5 \%$ of respondents say that their friends 'status updates motivate them to update their own social media accounts to be in limelight. It encourages them to have more likes and comments from their followers. The $15.18 \%$ respondents say that social media is not playing any role in this.

It is surprising that the majority (66.94\%) of respondents from Dhofar do not know any such organization which helps in branding Oman to attract tourists. The $31.59 \%$ say that it is Tourism Ministry who works to improve the tourism opportunities and tourism campaign in the Sultanate. Only $0.82 \%$ among all respondents says that Brand Oman Management Unit $(\mathrm{BOMU})$ is working in this direction. This data is very flabbergasted and shows that Salalah youths do not have sufficient knowledge and background about branding Oman, its objectives, and benefits.

In answer to the question about creating brand Oman through new media, $52.89 \%$ say that they do not know how they can do it, while, $47.11 \%$ say that government and citizens can utilize new media and different applications to promote country tourism. Ensuring online availability of a plethora of pictures, videos of mesmerizing landscapes, unexplored destinations, cultural heritage, and adventurous events can be supportive with advertising and sponsorship inside the country and abroad.

It has been observed with $52.06 \%$ of the responses that they are reluctant to answer about promoting tourism activities for mass tourism approach in Oman. It shows their frigid attitude towards tourism. During collection of data through WhatsApp group, few female members have started arguing. They believe that tourism brings crowd which creates many problems and increase accidents. Many of them think that tourists destroy the beauty of the place. They can affect the culture too. The $47.94 \%$ respondents say that Oman is a beautiful country, culturally and historically rich. So, we can utilize Oman beauty to attract tourists. To enhance mass tourism, we can start adventurous and interesting events. Local products like Omani female accessories and frankincense can be promoted.

When asked about the focus to encourage tourism elements, $52.89 \%$ respondents are reluctant to answer, while $47.11 \%$ respondents say that tourist destinations should be recreated and high level of online promotion should be done inside the country and outside. Explored the hidden potential of tourism should be uploaded online; more Omani travel agents should come forward to choose this profession and connect online with latent tourists.

In answer to local contribution in encouraging international tourism, $19.30 \%$ say that we should utilize expert knowledge to improve services and facilities to the tourists. The $31.58 \%$ respondents believe that different kinds of travel agencies should work online to facilitate international tourists with their needs. The 49.12\% suggests that good and attractive ideas should be invited from different sources to tourism authorities. The locals can participate in the government promotional campaign to brand the country. They say that language is also a barrier. The campaign needs to be focused on promoting international tourism.

The $50.83 \%$ respondents say that e-tourism is beneficial as it gives an opportunity to explore the country culture and encourages the sale related to that. While $11.67 \%$ say that it is easy for tourists to book everything online and start to their destination without any tension. The $37.50 \%$ of respondents say that etourism creates diversified demand for many things and 
contribute in collecting revenue for the country economy. In this way, it promotes SMEs also.

During observation, ten videos are reviewed. It has been noticed that the beauty of Oman is more explored, appreciated, and promoted online by outsiders rather than locals. It shows enough potential of Oman to grow as world-class tourism. During the present study, we have explored Dhofar news Instagram account too (@dhofar news, 2017). A video has been reviewed to find out why it is a matter of surprise to the locals. In that video, a European lady is practicing to walk on the rope between two mountains. She is surrounded by locals who are talking astonishingly about her. The comments are- "we never thought we can see it in real", "she is going to fall down" and "I thought it can happen only in TV shows" etc.

a) Findings

The findings present an insightful understanding of the present status of tourism, the pervasiveness of new media, and its significance in promoting worldclass tourism in Oman. The findings are:

1. Oman natural beauty and Tourism Ministry huge efforts have succeeded to lure the big number of tourists. After 2013, continuously increasing numbers of visitors in Oman prove that tourism industry is growing steadily. But to achieve the desired goal; it requires a change from higher-end tourism to mass marketing approach.

2. Despite all efforts of tourism Ministry and increasing penetration of new media in the Sultanate, social concern, awareness towards tourism benefits among Dhofar local youth are questionable. Their thinking and frigid attitude create a constraint in promoting tourism online.

3. The $71.1 \%$ accessibility of the internet has proven increasing use social media applications which can be helpful in facilitating tourists with different facilities. Higher view and hitting adds value to the content and provides digital statistics to help in promoting tourism advertising.

4. As responses show that young locals have lack of exposure regarding branding Oman. They themselves believe that there is immense scope in recreating destinations, travel and tour guide support and hospitality. The language and skills are also a basic requirement to promote international tourism.

5. To hold a position in the world-class tourism, we need to facilitate understanding among our youth about the benefits of tourism and connect them with different pieces of training and campaign projects. This will motivate them towards tourism and its subsections.

\section{Conclusion}

On the basis of the present study, the conclusion can be considered as recommendations. In order to support the government efforts, we need to motivate our young generation to join the hospitality sector and make them aware of the benefits of tourism. Brand Oman drive needs more push on local and international levels. To promote International tourism, different level of advertising campaign should be launched on inside the country and abroad. Sponsorship can be given to national and international events. Tourism and entertainment related training and workshops can be offered to break the frigid attitude of young locals. Additionally, more research can be promoted to explore new information regarding adventurous tourism in Oman. Professional training can be offered to tour guides and taxi drivers in terms of language and intercultural communication. Tourist destinations can be recreated so that regional tourism can be flourished during the whole year to support country GDP. Shortterm courses can be offered to young people to enhance the understanding about new media and its different implications as an informing tool rather that conversational tool.

\section{References Références Referencias}

1. Brand USA. (2016). Brand USA 'Market The Welcome' Campaign Unveiled at Miami International Airport. Retrieved from:http://www.prnewswire.com/ news-releases/brand-usa-market-the-welcomecampaign-unveiled-at-miami-international-airport300263638.html

2. Campaign Middle East. (2010). Oman launches an ad campaign for Dhofar Region. Retrieved from:http://campaignme.com/2010/08/02/1706/oma n-launches-ad-campaign-for-dhofar-region/

3. COMCEC. (2015). Effective Tourism Marketing Strategies: ICT-Based Solutions for the OIC Member Countries, COMCEC COORDINATION OFFICE, Retrieved from http://www.mod.gov.tr/Lists/ Recent Publications/Attachments/85/Effective\%20Tourism\% 20Marketing\%20Strategies,\%20ICT-Based\% 20Solutions\%20for\%20the\%200IC\%20Member\%20 Countries.pdf

4. Dhofar_News. (2017, January). European Tourist walking on a robe. [Instagram post]. Retrieved from https://www.instagram.com/p/BPA4zhfgkfZ/?hl=en

5. Food and Hospitality Oman. (2016.Oman Market report 2016. Retrieved from: http://isfahanfair.ir/ sites/isfahanfair.ir/foodoman.isfahanfair.ir/document s/2016/takmili.pdf

6. Go-gulf. (2015, November). Dubai Tourism Statistics and Trends. Retrieved from: http://www.go-gulf.ae/ blog/dubai-tourism-statistics-trends/ 
7. Hafiz Abad Institute of Business Administration. (2016) Brand Oman Management Unit. Retrieved from: https://www.coursehero.com/file/p21h763/ Brand-Oman-Management-Unit-BOMU-waslaunched-in-Oman-by-the-Public-Authority/

8. Internet Live Stats. (2017). Internet Users by Country (2016). Retrieved from: http://www.internetlivestats.com/internet-users-bycountry/

9. Jarshi, C. (2013) Significance of Social Media Marketing in Tourism, Research Gate. Retrieved from: https://www.researchgate.net/ profile/Charita_Jashi/publication/273145588_Signific ance_of_Social_Media_Marketing_in_Tourism/links/ 54fabaf-40cf2040df21cb17f.pdf

10. MacDonald, S. (2014). Oman Sets Sights on Tourism Industry. Retrieved from: http://www. aljazeera.com/news/middleeast/2014/05/oman-

sets-sights-tourism-industry-

2014510135247218917.html

11. NSCI. (2016). Khareef Season Results. Retrieved from: https://www.ncsi.gov.om/Elibrary/Library ContentDoc/bar_Khareef\%20Results\%202016_a6e7 b57e-fdb1-4b38-a0f9-e2a61708d68c.pdf

12. MEDIATE (2016) Nimble and Agile - the new world. Retrieved from:: http://mediate-oman.com/mediascene-2016-17/

13. MOT. (2016). Beauty has an Address. Retrieved from: http://www.omantourism.gov.om/ wps/portal/ mot/tourism/oman/home/!ut/p/a1/hc_LDolwEAXQb3 HBlg4ij7irilo8tRqxG4MGKwIQUIB-32rcmPiY3Z2cm8 wgilJE6-xWsKwreJ2Vj0zNgxnNgsSdahDbGoBH7NA kxNEhNiTYSwBfBsO_g7RJ3HmeDGyAtmZA54vrvy N3qoAdZelF6vyCxyRzCfGhIQK9puDRdgqL_AjxuWi LKSH5_7HF91G2GqMjPuciFehVyfem6phOroEDf9y rjnJW5euKVAp8qF952KH2XqKISKJJqZ7d44cAd9PYIf /dl5/d5/L2dBISEVZOFBIS9nQSEh/

14. Muscat Daily. (2015) Oman to See 11\% Growth form Tourism. Retrieved from: http://www.muscatdaily. com /Archive/ Oman/Oman-to-see-11-job-growthfrom-tourism-3y3l

15. Oman Turbine. (2016). 652,986 Visit Dhofar in Khareef. Retrieved from: http://omantribune.com/ details/14068/

16. ONA. (2016). 604,990 visit Salalah this Khareef Season. Retrieved form: http://www.muscatdaily. com/Archive/Oman/604-990-visit-Salalah-thiskhareef-season 4ssv\#ixzz 4VuZhRVvz

17. Tripathi. S. (2016). Changing Prospects of Advertising and Public Relations in GCC Countries: A Study with Omani Industrial Market. Paper Presented at the $2^{\text {nd }}$ World Conference on Media and Mass Communication (MEDCOM- 2016), Thailand. Retrieved from: http://mediaconference.co/2016/wpcontent/uploads/2016/05/Final-Abstract-BookMEDCOM-2016.pdf
18. Wippel, S. (2105, July). Salalah" Paradise": The Emergence of a new tourism Destination in Southern Oman. Centre for Mellemoststudier. Retrieved from: http://docplayer.net/39936021-Salalah-paradise-theemergence-of-a-new-tourism-destination-insouthern-oman-steffen-wippel.html

19. Zlatareva, N. (2015). Alternative and Mass Tourism Combination Analysis in South Europe. In Young Scientist USA, Vol. 2 (p. 40). Auburn, WA: Lulu Press. 